\title{
Producing quality beef: Practical experience, current practice and future direction
}

\author{
HOWARD DIXON', BOB THOMSON' and ARIE GRAAFHUIS ${ }^{3}$ \\ ${ }^{1}$ Dixon Farms, Ohaeawai, Northland \\ 2 Thomson Page \& Associates, Whangarei \\ ${ }^{3}$ Meat Industry Research Institute of NZ, Hamilton
}

\begin{abstract}
A bstract
A study is described which shows the need for a system to collect data that give farmers market signals related to meat quality, to enable them to make decisions on how best to achieve good returns from their animals. A case study is presented for one of eight Northland farms where on-farm handling, nutritional factors and transport factors that may affect meat quality has been monitored. The high variability of meat quality parameters between mobs from four farms is highlighted. For beef quality to improve, quality must be measured, and benefits to farmers and meat processing plants must be based on the quality of the product. A value-based payment system is strongly advocated, an essential requirement of which would be a beef trading database. Five main groups are identified which would provide input to the database: the seed-stock industry, commercial cattle breeders, cattle finishers, meat processors, and meat exporters. A national standard for describing beef quality is urgently required and is a prerequisite for any database.
\end{abstract}

Keywords: beef quality, case study, database, meat quality, monitor farms

\section{Introduction}

Most New Zealand beef ends up in the manufacturing sector, and particularly the US sector. However, some of the high quality meat from beef carcasses may end up as table meats in Asia and also in the New Zealand domestic market. New Zealand beef is being sold alongside quality Australian and US beef, much of which is grain-fed. Meat quality issues can arise when primal cuts are removed from carcasses that have been graded "manufacturing".

Reports indicate that Asians perceive New Zealand beef to have a grassy flavour, often to be too dark and not to be as succulent as other beef (Archibald 1993; NZMPB 1994). Apart from the fact that no detailed objective assessment of these perceptions has been made, anecdotal reports indicate that there is some truth to these comments.

Farmers who wish to produce beef for a specific market have little feedback available to indicate what practices they should be following. Assuming that the processing is optimal, many factors, from farm to slaughter, can affect meat quality through pre-slaughter stress. Bray et al. (1988) and Devine et al. (1994) have found that pre-slaughter stresses are cumulative in their effects on meat quality. This has important implications for avoiding stresses, in that no single factor is necessarily to blame and that all sectors of the industry must work together to produce high quality beef. Addressing the consequences of pre-slaughter stresses will probably do more to unify the production and processing sectors of the meat industry than any other issue.

The first important step in addressing this issue was to quantify the incidence of animals with an elevated ultimate $\mathrm{pH}$ under the present commercial conditions in New Zealand. The results were reported at the most recent Meat Industry Research Conference (Graafhuis \& Devine 1994). This study found that the mean ultimate $\mathrm{pH}$ for prime steer was $5.59,93.9 \%$ of values being less than $\mathrm{pH} 6.0$, whereas for bull beef, the mean ultimate $\mathrm{pH}$ was 6.16 , only $40.8 \%$ of values less than $\mathrm{pH}$ 6.0.

A cut-off value of $\mathrm{pH} 6.0$ is used because meat of that $\mathrm{pH}$ or higher will spoil more rapidly in chilled vacuum packs due to microbiological deterioration. In fact meat colour may have deteriorated considerably well before this $\mathrm{pH}$ value is reached, and additional toughness problems may be present. Although in the recent study the range of ultimate $\mathrm{pH}$ values obtained for steers was considerably better than for bulls, in light of the quality problems (colour, toughness etc.), many carcasses were still unacceptable. For bull beef, the implications for overall meat quality were even more serious. Even though the live animals look to be of good quality, this does not give any guide to meat quality and objective information is needed to plan a stratergy to ensure high quality beef is produced 
appropriate to the market. As well, increasing muscle $\mathrm{pH}$ affects other meat quality attributes, such as juiciness, flavour, and cooking and binding properties. Even when the range of $\mathrm{pH}$ values is not large, the resultant variability may compromise the quality for discerning markets.

In a second step to address the stress-meat quality issue, the Meat Industry Research Institute of New Zealand (MIRINZ) initiated a study that is focusing on on-farm handling, nutritional factors and transport factors, that may affect meat quality. This study, based with Thomson Page and Associates in Whangarei, involves several Northland farms. Carcass assessments are being carried out by the meat plant, so on-farm and transport effects may be related to meat quality.

This study, funded by the Meat Research and Development Council (MRDC), signals the start of a measuring system to collect data that give farmers market signals related to meat quality, to enable them to make the decisions on how best to achieve good returns for their animals. This measuring system cannot be regarded definitive, but it will provide information to form a baseline for improvements. Such a system is not in place in most New Zealand processing plants, although some companies have developed their own databases. It should be stated at this stage that information on animal weight and grade are essentially irrelevant in terms of meat quality. The final outcome will not necessarily be a written document, but rather a technology transfer effort that is based on sound information to help farmers to meet the demands required of them. It therefore involves personal contacts that should be continually expanding.

\section{M eat quality}

"Quality" is defined as fitness for purpose. "Meat quality" is therefore eating quality. While farmers have always thought they produced good "quality" animals, with a few ribbons from shows and carcass competitions to their credit, they have only recently been able to obtain some objective measurements on meat quality aspects and possibly to appreciate that actions taken on the farm may influence the final outcome of the meat itself.

East Asia offers an excellent opportunity for quality beef. To make the most of this opportunity, New Zealand exporters need more prime animals that meet an allinclusive range of specifications. For the Japanese market the specifications are as follows:

$\begin{array}{ll}\text { Japanese market } & \text { quality parameters } \\ \text { weight } & 305-360 \mathrm{~kg} \\ \text { grade } & \mathrm{P}, \mathrm{K} \text { or } \mathrm{G} \text {. (Fat depth ; } 4-18 \mathrm{~mm} \text { fat) }\end{array}$
fat colour
1-5 (Japanese scale of 1-7)
( $1=$ white, 7 = yellow)
meat colour
1-5 (Japanese scale of 1-7)
$\mathrm{pH}$
$(1=$ bright red, $7=$ dark red $)$
$<5.8$

\section{The Current Situation in Northland}

\section{Stock management reports}

Stock management reports were initiated at AFFCO Moerewa. The key to this system is a computer touchscreen in the killing area so that ear tags and brands can be entered alongside the carcass number, which is used as a basis when recording all subsequent data. Grading of the hot carcass supplies information on grade, sex, dressed weights, conformation class and an indicative recording of fat depth. Fat colour, meat colour and $\mathrm{pH}$ are recorded in the chiller some 12-24 hours post slaughter.

\section{Pasture minimum and maximum growth rates}

One factor that can be a stressor is poor and/or insufficient feed. In Northland, pasture growth rates can be highly variable (Figure 1.). This reflects the Northland climate, which can produce spring droughts and late summer floods. High growth rates are possible in wet summers, but with soils that are prone to drying out, growth rates in a dry summer are lower than those usually obtained in winter. By using winter growth pasture species on free-draining soils, heavy cattle can be finished throughout the winter.

All cattle are purchased, preferably over $400 \mathrm{~kg}$ live weight from 12 to 30 months of age. A mixed portfolio of mainly traditional beef breeds, some exotic crosses and a few dairy-beef are finished. The objective is to finish more than 500 head per year at above $320 \mathrm{~kg}$ average carcass weight. Stocking rates vary between 280 head in dry summers to 420 head during autumn and spring.

Figure 1 Pasture growth rates - Waimate North phosphate trials.

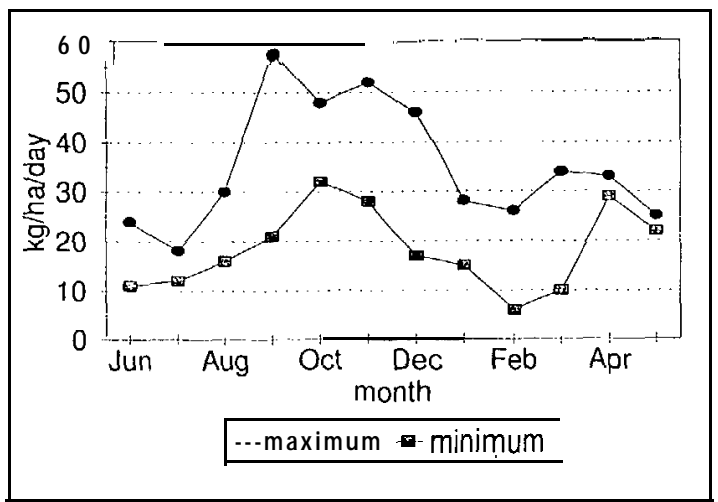




\section{Case Study}

\section{Case study farm - beef unit}

(For more detail, see field trip booklet)

This report discusses a case study farm that is one of eight Northland monitor farms in the MIRINZ survey. These monitor farms and case study were set up because although some farmers had started receiving carcass feedback and had some rewards for meeting specifications in their supply contract with AFFCO Moerewa, not many farmers were sure of what they could do to improve meat quality. Involvement in the survey offered an opportunity to learn.

Although the case study is the focus of this paper, a broader description of the MIRINZ study as a whole is given, to put the discussion of the case study in perspective.

The entire study takes in 160 grazeable hectares of volcanic soils between Ohaeawai and Waimate North. Soils are predominantly Ohaeawai bouldery silt loam with areas of Waiotu friable clay and Waimate North clay loam. Pastures are essentially permanent ryegrassclover based, with paspalum contributing in summer. Management includes a vigorous programme to prevent invasion of kikuyu. The aim is to maintain high soil fertility (Olsen phosphate values of 20-30).

\section{Stock management}

Stock management on a finishing farm requires lines of purchased cattle to be boxed together with similar cattle to make up mobs, the size of which is dictated by ground conditions. On the case study farm, larger mobs of growing cattle follow smaller groups of larger finishing cattle in a leader-follower grazing system to maintain pasture quality.

Each line purchased is given a code that is cross referenced to tag numbers. This means that when data from the farm's stock management reports are entered onto a multidimensional database, the data can be sorted by breeder, by breed, by feed conditions prior to slaughter, or by any other parameter that is desired.

Objective information is useful only if there is knowledge of the origin of the stock. Preference has always been to purchase straight lines with breeder identification. A prerequisite to this is individual animal identification. Formulas have been established for purchase on a liveweight basis with information exchange a key feature. As marketing targets are met, the purchasing criteria may need to change, to reward quality supply.

\section{Data gathering - MIRINZ study}

Information on stock from the eight Northland monitor farms was collected at AFFCO NZ Ltd., Moerewa Plant, and Weddel NZ Ltd., Whangarei Plant, until that plant went into receivership. Regular meetings were arranged with farmer groups, particularly those from the monitor farms, in collaboration with the appropriate meat plant personnel to ensure farmers and meat company personnel understood what information and data were required. An attempt was made to assess all stock coming off the monitor farms and an essential component of this programme was the transfer of appropriate information to all involved. The following data were collected:

On-farm data:

Farm size, type of country, and type of farm.

Type of cattle, mob size, and timing of de-horning.

Use of growth promotants.

Feed conditions, feeding-out practices, and recent nutritional history.

How long the cattle were on the farm.

An estimate of the minimum distance at which the animals reacted to human presence (cattle's flight distance).

At mustering:

The weather conditions such as air temperature and pressure, wind and rain, and recent conditions.

An evaluation of the mustering procedure, yarding facilities and loading ramps.

The extent of animal handling, and whether the mobs were split or combined.

At the time of transport:

Name of the carrier.

Distance and time travelled, the nature of the route, and any stops en route.

The number of cattle per pen, tightness of packing, and any other mobs on the truck.

Weather conditions during the trip.

At the meat plant:

Date, distance travelled, time of travel, mob size, breed and detention.

Carcass weight, grade.

Ultimate $\mathrm{pH}$, meat colour, fat colour and an assessment of carcass bruising.

All ultimate $\mathrm{pH}$ values were measured on the striploin at 24 hours post mortem using a calibrated Orion Ross spear electrode (83-63) attached to an Orion SA250 meter. Meat colour and fat colour were assessed visually against a standard similar to that used by AusMeat in the chiller at 24 hours post mortem. Carcass bruising was assessed at four significant carcass sites (butt, rump, loin, and forequarter blade) immediately after hide removal, using a scoring system that recorded the degree of bruising damage. 


\section{Results}

Farm stock management reports

Analysis of stock management reports over the first 12 months showed that $27 \%$ of cattle met the meat processor's specification package for Japan as assessed by the grader. The range of results for lines of cattle achieving the target specifications from individual breeders ranged from $0 \%$ to $90 \%$. Tables 1 and 2 show the types of variation found in the measured meat quality parameters, in monitored and unmonitored farm management systems from four separate mobs.

In Table 1, the data for mob 1 shows how results can be highly variable when the origin and history of the animals are not available. For this mob, all the meat quality parameters (fat depth, fat colour, meat colour and ultimate $\mathrm{pH}$ ) showed wide variation, and only three carcasses were suitable for selection by the Japanese grading system. Mobs 2 and 3 are both examples of a poor line, especially for fat colour. These mobs are good examples of the consistency problem faced by a meat grader with fat colour. Groups such as these still have the potential to meet "quality" specifications if ultimate $\mathrm{pH}$ values less than $\mathrm{pH} 5.8$ had been achieved, providing the fat is not too yellow (e.g., mob 2).

Before the advent of stock management reports, information on how a farmer was performing with regard to meat quality market signals was not available.

Table 2 gives data for a mob of cattle of known history. Appropriate management practices coupled with a continuing measurement programme both on-farm and subsequently at the meat plant, have allowed the farmer to focus on the target market signals, and over time improvements have evolved. In this example, two carcasses fell outside the carcass weight range, three
Table 1 Meat quality parameters of three mobs of unknown history.

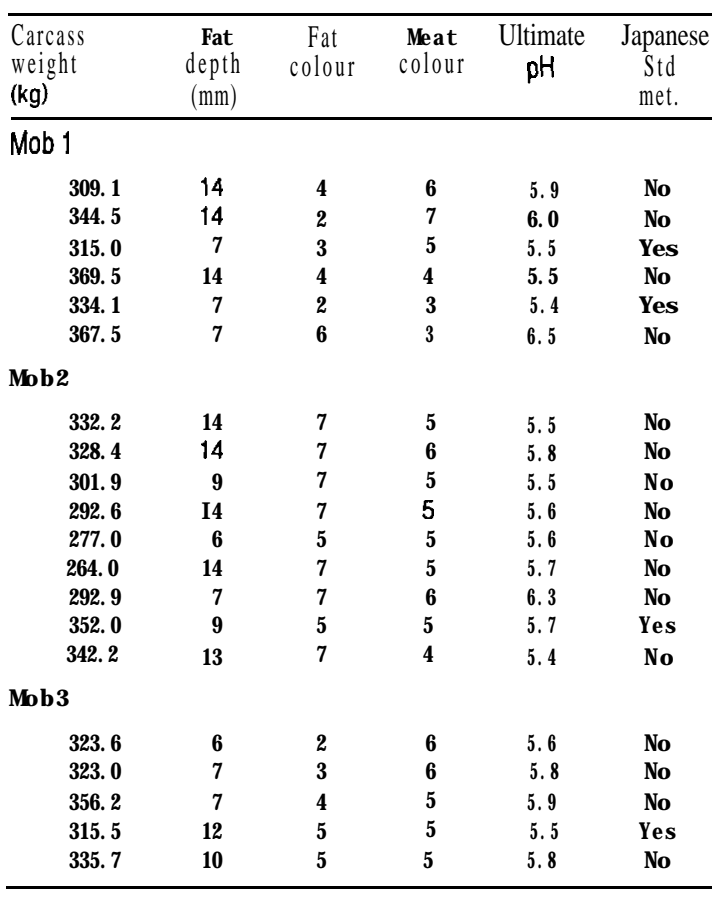

were outside the range for fat depth, and one carcass each exceeded fat colour, meat colour and ultimate $\mathrm{pH}$. Overall, of the 18 carcasses, 10 met the Japanese quality standards for which they were aimed. Although this performance may not appear to be significantly better than other mobs, it has been achieved by design, which will allow the farmer to make incremental improvements over time.
Table 2 Meat quality parameters of a mob of known history.

\begin{tabular}{|c|c|c|c|c|c|c|c|}
\hline $\begin{array}{c}\text { Tag } \\
\text { number }\end{array}$ & $\begin{array}{c}\text { Carcass } \\
\text { wgt (kg) }\end{array}$ & $\begin{array}{l}\text { Fat depth } \\
(\mathrm{mm})\end{array}$ & $\begin{array}{l}\text { Fat } \\
\text { colour }\end{array}$ & $\begin{array}{l}\text { Meat } \\
\text { colour }\end{array}$ & $\begin{array}{l}\text { Ultimate } \\
\mathrm{r} \text { pH }\end{array}$ & Breed & $\begin{array}{l}\text { Japanese } \\
\text { Std. Met. }\end{array}$ \\
\hline 34 & 338.7 & 13 & 6 & 5 & 5.5 & $A^{\star} S L / A$ & No \\
\hline 26 & 342.9 & 13 & 4 & 5 & 5.5 & $A^{\star} S L /\left(F^{\star} H\right)^{\star} A$ & Yes \\
\hline 16 & 346.2 & 19 & 5 & 4 & 5.7 & $A^{\star} S L / 3 / 4 A^{\star} D$ & $\mathbf{N b}$ \\
\hline 15 & 323.7 & 19 & 5 & 5 & 5.5 & $A^{*} S L / J^{*} H$ & $\mathrm{~N}_{0}$ \\
\hline 18 & 331.4 & 8 & 5 & 4 & 5.6 & AxSL/A & Yes \\
\hline 19 & 346.3 & 19 & 5 & 5 & 5.6 & $A \times S L /\left(F^{\star} H\right)^{\star} A$ & $\mathrm{~N}_{0}$ \\
\hline 30 & 323.7 & 5 & 4 & 3 & 5.6 & $A^{\star} S L /\left(C C^{\star} F\right)^{*} A$ & Yes \\
\hline 29 & 334.4 & 7 & 5 & 3 & 5.5 & $A^{*} S L / A^{*} D$ & Yes \\
\hline 7 & 323.6 & 6 & 4 & 5 & 5.7 & $A^{\star} S L / 3 / 4 A^{\star} D$ & Yes \\
\hline 24 & 340.5 & 5 & 4 & 5 & 5.7 & $A * S L * A$ & Yes \\
\hline 3 & 328.3 & 9 & 3 & 5 & 5.8 & $A^{*} S L / A^{*} D$ & No \\
\hline 22 & 355.1 & 9 & 5 & 3 & 5.5 & A'SLIA & Yes \\
\hline 2 & 333.2 & 15 & 4 & 4 & 5.5 & $A^{*} S L / 3 / 4 A^{*} D$ & Yes \\
\hline 10 & 319.8 & 7 & 4 & 4 & 5.5 & $A^{*} S L / F^{*} H$ & Yes \\
\hline 40 & 298.0 & 5 & 4 & 5 & 5.6 & $A^{*} S L / A$ & $\mathbf{N b}$ \\
\hline $\begin{array}{l}8 \\
9\end{array}$ & $\begin{array}{l}316.3 \\
364.9\end{array}$ & $\begin{array}{l}5 \\
7\end{array}$ & $\begin{array}{l}5 \\
4\end{array}$ & $\begin{array}{l}5 \\
5\end{array}$ & $\begin{array}{l}5.6 \\
5.6\end{array}$ & $\begin{array}{l}A^{*} S L / A^{*} D \\
A^{*} S L / A^{*} D\end{array}$ & $\begin{array}{l}\text { Yes } \\
\text { No }\end{array}$ \\
\hline 1 & 357.3 & 13 & 5 & 6 & 5.8 & $A^{*} S L / A^{*} D$ & No \\
\hline
\end{tabular}

\section{Overview of MIRINZ's findings}

\section{Ultimate $\mathbf{p H}$}

MIRINZ has so far studied four monitor farms in detail. The mean $\mathrm{pH}$ values of the beef from these farms ranged from 5.5 to 6.1 . At the two extremes, for one farm $100 \%$ of the $\mathrm{pH}$ values values were less than $\mathrm{pH} 5.8$, whereas for another (a bull farm) $21 \%$ were less than $\mathrm{pH} 5.8$. Clearly there are significant differences between farms, which will highlight management practices, animal differences and mob and transport issues contributing to high $\mathrm{pH}$ carcasses. 


\begin{abstract}
Meat colour
The farm that had the highest incidence of high $\mathrm{pH}$ also showed the widest variation in meat colour. The results from the other farms, where most of the ultimate $\mathrm{pH}$ values were less than $\mathrm{pH} 5.8$, showed that normal ultimate $\mathrm{pH}$ carcasses were often assessed as being darker than they may have been had there been a range of high $\mathrm{pH}$ carcasses to compare them with. Such inconsistent colour data, which may be due to the poor lighting conditions in chillers (where colour is assessed), if sent back to a farmer, could be confusing. Indications are that meat colour may be as sensitive to animal stress as is ultimate $\mathrm{pH}$, so all management changes aimed at lowering $\mathrm{pH}$ will also improve meat colour. To achieve better meat colour, farmers may need to provide higher energy feeding leading up to slaughter.
\end{abstract}

\section{Fat colour}

Whether an animal has yellow fat is determined genetically and is influenced by the level of carotene in the feed. Dry weather spells cause a hardening of pasture and a decrease in carotene and xanthophyll levels. The month of August appears to be the worst, and January the best. Stock management reports indicate that there is a seasonal effect on fat colour. Indications are that supplementary feeding on grains, e.g., feedlot cattle, for 100 days improves the fat colour significantly. However, this may not be practical or economic in Northland's climate, although this is not to say it cannot be achieved in the future. Before providing supplementary feed or planting specialist crops, we need more detailed technical and financial information.

\section{Animal breed}

No obvious sire breed effects have been noticed on meat colour, although more accurate data and more individual identifications are needed. Indications are that younger pure bred Angus and Hereford cattle are more likely to give good fat colour. However, the data are still highly variable, and there is not enough individual identification and sire trace-back. In terms of tenderness, pre-slaughter stress, electrical stimulation, aging and chiller temperatures have more effect than genotype. Breeders have to be confident that their processors are doing their part.

\section{Discussion}

The energy produced by the feed supply can be used most efficiently by taking each animal to the carcass weight and fat depth required by the target market. The breed and growth curve determines which market each animal will be suitable for. Any "over finishing" is a wasted effort that will cost the farmer as a price penalty when grades are not met. Most markets include specifications for age, carcass weight and fat depth: the Japanese market also has specifications for carcass $\mathrm{pH}$, and meat and fat colour. The breeder is faced with producing an animal to an ideal frame size, muscling and maturity type.

For Asian markets, both product appearance and supply must be consistent. Tight market specifications make continuous supply more difficult for grass-fed finishing, and specialised finishers are better placed to combine lines for consistent supply. Cross breeding with large exotic terminal sires and smaller traditional sires also tends to make producing a consistent target carcass weight and size more difficult.

Farmers must aim to produce a quality product which is tender, juicy, flavoursome and acceptable to the appropriate markets. All sectors of the beef industry must work together to achieve this. Changes in the beef classification system and the feedback of data relating to meat quality can be used to allow farmers to response to appropriate market signals. Carcass weight and grade alone will not do this. Issues such as detention need to be included in the data assessment criteria. Some farmers have trading practices where documentation is not adequate for the animals' age, and when the animals are subsequently slaughtered, they are found to be older than claimed.

The belief that poor performance is genetic is inaccurate. Genotype plus feeding plus pre-slaughter stresses have major influences on whether a carcass meets market specifications.

\section{Future directions}

Future opportunities are with a value-based payment system. Such a system would have as an essential requirement a Beef Trading Information Database. For improvements to occur, measurements must be made, and benefits to farmers and meat processing plants must be based on the quality of the product.

Five main groups would provide an input to a Beef Trading Information Database: the seed stock sector, the commercial cattle breeders, the cattle finishers, the meat processors, and the meat exporters.

An effective seed-stock module would require a centralised database, or at least an electronic connection between the various breed societies and the central database. The seed-stock sector (registered sector) does not keep track of the use of bulls. A system that tracks bulls from the seed-stock sector to the commercial breeder and finisher is needed. Clear price relationships must be conveyed to farmers for product meeting inclusive ranges of specifications. A national standard, based on all measurements required to grade carcasses, 
is a prerequisite. Individual market-based and producer relationships can then be developed, based on the objective measurements.

\section{Conclusions}

Specialised finishing properties are able to combine lines of cattle for consistent supply for slaughter. Valuebased payment systems will lead to more value-based contracts.

There is also a need for seed-stock producers to recognise that beef quality traits must be included in their selection objectives. The traits currently available are eye muscle area and fat depth, which, when combined with liveweight, can be used for predictions of lean meat yield. Recorded traits will need to be expanded to fat colour, meat colour and possibly marbling. These traits can be measured only in slaughter animals, so strong links are needed between commercial breeders and finishers and the meat processors. Also, a simple on-farm performance recording scheme is needed to capture important carcass quality traits.

Management procedures that aim to produce a specific beef quality and value are at least equally important. Two keys areas are stock handling and nutrition, as already noted. Improvement in this area will offer the most promising short term gains to beef quality.

The current beef classification system does not provide any meat quality specifications. Some processors provide meat quality assessments on a voluntary basis, but this information is not standardised between plants. A national standard for describing beef quality is urgently required before a Beef Trading Information System could operate. Video Image Analysis would allow an objective measurent system to be developed.

A Beef Trading Information Database system is urgently required, to trace livestock from the seed-stock producer, to the finisher and through to the market. An essential ingredient will be a national standardised and audited set of criteria so that marketers can describe the range of specifications they need. Payments can then be based on objective measurements.

Processors will gradually identify preferred suppliers. These suppliers will provide cattle to quality specifications on a consistent basis. For a supplier to maintain preferred supplier status will require a continuous and improving number of carcasses meeting specification.

It comes down to a personal risk analysis of the likelihood of maintaining preferred status, the amount of premium likely and the cost of changing management practices to achieve this.

\section{ACKNOWLEDGEMENTS}

A number of people have contributed to helping in the various trials, analysing data and preparing this report. As such, we acknowledge the cooperation of the following companies: AFFCO NZ Ltd., Whangarei and Moerewa plants, and Weddel NZ Ltd., Whangarei plant. We also thank Clare Kokich, the eight Northland farmers, and colleagues at MIRINZ for their assistance. This study was funded by the New Zealand Meat Research and Development Council.

\section{REFERENCES}

Archibald, R.D. 1993. Business Opportunities in South East Asia, Report on trip to Singapore, Malaysia, and Hong Kong, June 1993, MIRINZ Internal Report No. 344.

Bray, A.; Graafhuis, A.E.; Chrystall, B.B. 1988. The cumulative effect of nutritional, shearing and preslaughter washing on the quality of lamb meat. Meat Science 25: 59-67.

Devine, C.E.; Graafhuis, A.E.; Muir, P.D.; Chrystall. B.B. 1993. The effect of growth rate and ultimate $\mathrm{pH}$ on meat quality of lambs. Meat Science 36: $143-150$.

Graafhuis, A.E.; Devine, C.E. 1994. Incidence of high $\mathrm{pH}$ beef and lamb II: Results of an ultimate $\mathrm{pH}$ survey of beef and sheep plants in New Zealand. Proc, 28th Meat Industry Research Conference, Hamilton.

New Zealand Meat Producers Board. 1994. Qualitative Research Survey on Meat in Singapore and Malaysia, May 1994. 